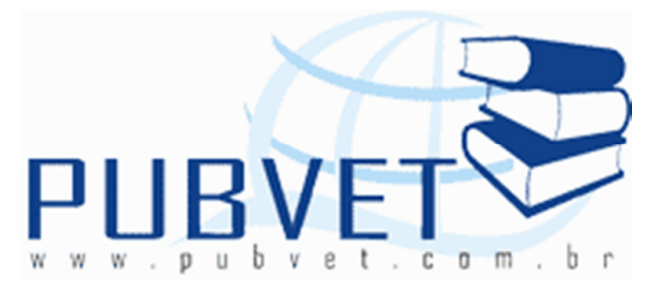

PUBVET, Publicações em Medicina Veterinária e Zootecnia.

\title{
Avaliação da incubação artificial de ovos deformados em matrizes pesadas
}

\section{Ellen Rovaris ${ }^{1}$, Gerusa da Silva Salles Corrêa ${ }^{2}$, André Brito Corrêa ${ }^{2}$, João Garcia Caramori Junior ${ }^{2}$, Uanderson Verrissímo de Luna ${ }^{1}$, Saullo Diogo de Assis ${ }^{1}$}

Mestrandos do programa de pós-graduação em Ciência Animal, Universidade Federal de mato grosso, UFMT, Cuiabá, MT. E-mail: ellenrovaris@hotmail.com. ${ }^{2}$ Profs. Drs. Adjuntos Dept $^{\circ}$ de Ciências Básicas e Produção Animal, FAMEV/ UFMT, Cuiabá, MT.

\section{Resumo}

Com o objetivo de avaliar a eclodibilidade de ovos férteis defeituosos e verificar a viabilidade da incubação dos mesmos, incubou-se ovos que foram divididos em 6 tratamentos, tratamento 1: ovos tortos, tratamento 2: ovos pequenos (45 a 47g), tratamento 3: ovos com microtrincas, tratamento 4: ovos com densidade considerada baixa (1070), tratamento 5: ovos considerados ideais para a incubação porém posicionados na bandeja com o pólo invertido (câmara de ar para baixo) e tratamento 6: controle, ovos considerados ideais para incubação. Os resultados demonstraram que o tratamento controle apresentou os maiores índices de eclodibilidade e menor mortalidade embrionária.

Palavras-chave: eclodibilidade, frangos de corte, incubatório, mortalidade embrionária. 
ROVARIS, E. et al., Avaliação da incubação artificial de ovos deformados em matrizes pesadas.

PUBVET, Londrina, V. 8, N. 18, Ed. 267, Art. 1777, Setembro, 2014.

\title{
Evaluation of artificial incubation of eggs for broiler breeders deformed
}

\begin{abstract}
White the goal of evaluate the hatchability of defective fertile eggs and verify the viability of the same incubation, incubated eggs were divided into6 treatments, treatment 1: eggs crooked, treatment 2: small eggs(45 to $47 \mathrm{~g})$, treatment 3:eggs with microcracks, treatment 4: eggs considered low density(1070), Treatment 5:eggsfor incubation considered ideal but placed in the tray with the pole inverted(tube down) and treatment 6: control, eggs considered ideal hatching. The results showed that the control treatment had the highest rates of hatchability and reduced embryo mortality.
\end{abstract}

Keywords: broiler, embryo mortality hatchery, hatchability.

\section{Introdução}

O ovo da galinha é uma célula reprodutiva e para a criação de frangos em escalas comerciais, estas células também devem ser produzidas em escala comercial, e não existem dúvidas de que a incubação artificial substitui a galinha de maneira muito mais eficiente (SILVA, 2005).

O incubatório é um ambiente estratégico da produção avícola e está fortemente vinculado à granja de matrizes (GONZALES, 2003). A principal meta do incubatório é transformar biologicamente ovos férteis em pintos de um dia no volume, prazo e qualidade desejados, minimizando a incidência de anormalidades e contaminação, de forma a atender às necessidades e expectativas da produção avícola, ao menor custo (TONA et al., 2003).

Para se ter um bom nascimento de pintinhos, o processo inicia-se pelo bom manejo na coleta de ovos na granja e seu transporte até o incubatório. Os ovos após realizada a coleta nos aviários devem ser enviados para um depósito na granja e em seguida para um depósito no incubatório, através do transporte por um caminhão climatizado. É importante que todos estes lugares 
ROVARIS, E. et al., Avaliação da incubação artificial de ovos deformados em matrizes pesadas. PUBVET, Londrina, V. 8, N. 18, Ed. 267, Art. 1777, Setembro, 2014.

tenham ambiência semelhantes para evitar mudanças bruscas na temperatura e umidade no ovo (COBB-VANTRESS, 2008).

Normalmente descarta-se ovos que apresentem pouca chance de eclosão, e que impliquem em pintinhos de baixa qualidade, como ovos muito grandes ou muito pequenos, trincado, sujos, deformados entre outros fatores. Ovos de boa qualidade devem ser provenientes de aves saudáveis, livre de microorganismos, boa espessura de casca, forma ovoidal, ser fértil, não apresentar deformidade e nem trincas (COBB-VANTRESS, 2008).

Entretanto, ainda existem dúvidas quanto às quais tipos de ovos realmente devem ser descartados.

O objetivo deste trabalho foi avaliar a viabilidade na utilização de ovos defeituosos no processo de incubação artificial.

\section{Material e métodos}

Foram incubados 344 ovos tortos, 344 ovos pequenos (entre 45 e $47 \mathrm{~g}$ ), 430 ovos com microtrincas, 430 ovos com densidade de 1070, 430 ovos com o pólo fino virado para cima e 1080 ovos considerados de boa qualidade para incubação (controle), representando os tratamentos 1, 2, 3, 4, 5 e 6, respectivamente. Esta incubação foi realizada em incubatório industrial. Com os ovos incubados na mesma incubadora, no mesmo dia, portanto submetidos às mesmas condições de incubação.

Os ovos foram selecionados no incubatório, provenientes de matrizes da Linhagem $\mathrm{Coob}^{\mathrm{R}}$, armazenados por 4 dias à $20^{\circ} \mathrm{C}$ e umidade de 75 a $85 \%$, posteriormente encaminhados ao pré-aquecimento por 6 horas antes da incubação em sala específica para esta finalidade a uma temperatura de $28^{\circ} \mathrm{C}$ sendo que a temperatura dos ovos foi monitorada por termômetro de raio infravermelho. Após o pré-aquecimento foram colocados na incubadora de múltiplo estágio, a temperatura de $37,3^{\circ} \mathrm{C}$ e umidade de 50 a $60 \%$, a qual foi mantida por bicos pulverizadores, viragem automática de $45^{\circ}$ a cada hora. Aos 19 dias de incubação foram transferidos para o nascedouro a temperatura de 
ROVARIS, E. et al., Avaliação da incubação artificial de ovos deformados em matrizes pesadas. PUBVET, Londrina, V. 8, N. 18, Ed. 267, Art. 1777, Setembro, 2014.

$36^{\circ} \mathrm{C}$ e umidade de $87 \%$. A temperatura e umidade foram monitoradas em todo o processo.

Para separação dos tratamentos, separou-se visualmente o tratamento 1 ovos tortos, considerou-se que ovos pequenos (tratamento 2 ) eram aqueles com peso entre 45 e $47 \mathrm{~g}$, os ovos do tratamento 3 foram selecionados em sala escura com auxílio de lanterna para visualizar as microtrincas, o tratamento 4 ovos com densidade de 1070 foram selecionados através da prova da densidade com a inclusão de cloreto de sódio ( $\mathrm{NaCl}$ ) na água e medições através do densímetro, os incubados com pólo invertido (tratamento 5 ) e os ovos controle (tratamento 6 ) foram os ovos que pesavam entre $48 \mathrm{~g} \mathrm{e}$ $70 \mathrm{~g}$, não apresentavammicrotrincas, de forma ovóide e densidade de 1080, sendo que o tratamento controle foi incubado com a câmara de ar virada para cima.

As incubadoras foram higienizadas e desinfetadas três vezes por semana e nos nascedouros colocados $150 \mathrm{ml}$ de formol líquido a cada 7 horas.

Aos 12 dias de incubação foi realizada a ovoscopia, retirados os ovos claros (com embrião morto ou inférteis) e realizada a quebra para realizar o embriodiagnóstico. Após aos 21 dias de incubação quando da eclosão avaliouse a porcentagem de nascimento de pintos viáveis, números de pintos de segunda, contaminação por fungo e bactéria, mortalidade embrionária de 0-4, 5 - 10 e 11-21 dias de idade, através da análise de resíduos e quebra dos ovos não eclodidos.

Foram descartados os ovos inférteis e somente foram considerados os férteis. Os índices de eclodibilidade de pintos viáveis(PV), pintos de segunda(PS), contaminação(C), mortalidade embrionáriade 0 a 4(M1), 5 a 10(M2) e 11 a 21(M3) foram obtidos a partir de: PV= PV/TO (Total de ovos férteis) $* 100 ; \mathrm{PS}=\mathrm{OS} / \mathrm{TO}) * 100 ; \quad \mathrm{C}=\mathrm{C} / \mathrm{TO} * 100 ; \mathrm{M} 1=\mathrm{M} 1 / \mathrm{TO} * 100 ; \mathrm{M} 2=$ $\mathrm{ME} / \mathrm{TO} * 100 ; \mathrm{M} 3=\mathrm{M} 3 / \mathrm{TO} * 100$.

O delineamento utilizado foi o inteiramente casualizado (DIC) e os dados foram submetidos a análise descritiva. 
ROVARIS, E. et al., Avaliação da incubação artificial de ovos deformados em matrizes pesadas.

PUBVET, Londrina, V. 8, N. 18, Ed. 267, Art. 1777, Setembro, 2014.

\section{Resultados e discussão}

Os resultados da eclosão de pintos viáveis, pintos de segunda, mortalidade embrionária 0 a 4, 5 a 10,11 a 21 e contaminação dos ovos incubados com diferentes defeitos estão apresentados na tabela 1.

Tabela 1. Índices de eclosão, pintos de $2^{a}$, contaminação e mortalidade embrionária nas diferentes fases de desenvolvimento.

\begin{tabular}{|c|c|c|c|c|c|c|}
\hline Índices & $\begin{array}{c}\text { Ovos } \\
\text { tortos } \\
(\%)\end{array}$ & $\begin{array}{c}\text { Ovos } \\
\text { pequenos } \\
(42 \text { a } \\
47 g)(\%)\end{array}$ & $\begin{array}{c}\text { Ovos com } \\
\text { microtrincas } \\
(\%)\end{array}$ & $\begin{array}{l}\text { Ovos com } \\
\text { densidade } \\
1070(\%)\end{array}$ & $\begin{array}{c}\text { Ovos com } \\
\text { pólo } \\
\text { invertido } \\
(\%)\end{array}$ & $\begin{array}{c}\text { Controle } \\
(\%)\end{array}$ \\
\hline $\begin{array}{c}\text { Eclosão de } \\
\text { pintos viáveis }\end{array}$ & 82,05 & 85,76 & 73,73 & 84,89 & 53,08 & 91,11 \\
\hline Pintos de $2^{a}$ & 3,48 & 2,03 & 2,8 & 1,16 & 23,34 & 0,48 \\
\hline Contaminação & 0,58 & 0 & 1,16 & 1,63 & 0 & 0,38 \\
\hline $\begin{array}{c}\text { Mortalidade } \\
\text { embrionária } 0 \\
\text { a } 4 \text { dias }\end{array}$ & 7,20 & 5,81 & 8,83 & 6,51 & 3,94 & 3 \\
\hline $\begin{array}{c}\text { Mortalidade } \\
\text { embrionária } 5 \\
\text { a } 10 \text { dias }\end{array}$ & 2,32 & 2,33 & 3,02 & 1,63 & 1,16 & 1,16 \\
\hline $\begin{array}{l}\text { Mortalidade } \\
\text { embrionária } \\
11 \text { a } 21 \text { dias }\end{array}$ & 4,37 & 4,07 & 10,46 & 4,18 & 18,47 & 3,87 \\
\hline
\end{tabular}

Observa-se que a eclosão de ovos com características dentro da normalidade foi superior as eclosões dos ovos que apresentavam alguma 
ROVARIS, E. et al., Avaliação da incubação artificial de ovos deformados em matrizes pesadas. PUBVET, Londrina, V. 8, N. 18, Ed. 267, Art. 1777, Setembro, 2014.

anormalidade, assim como para os outros índices, com exceção da contaminação, que ovos pequenos e com o pólo invertido apresentaram $0 \%$ para este índice, enquanto os ovos controle apresentaram 0,38\%. Os maiores índices de contaminação foram dos ovos tortos com $0,58 \%$ seguidos dos ovos com microtrincas $(1,16 \%)$ e com densidade de $1070(1,63 \%)$.

Santos et al. (2007) estudando a incubação de ovos com diferentes defeitos também obtiveram melhores índices de eclosão em ovos com boa qualidade de casca $(82,9 \%)$.

Ovos com densidade de 1070 possuem espessura mais fina e maior porosidade alterando a condutância da casca, isto explica o maior grau de contaminação dos embriões e a maiores perdas de peso no período de incubação (ROSA E ÁVILA 2000; TANURÉ; CAFÉ; BAIÃO, 2009).

Ovos de matrizes mais velhas têm maior freqüência de ovos maiores, ocorrendo redução da densidade, devido à maior porosidade da casca, que favorece as trocas gasosas entre ovo e meio. Mcdaniel et al., (1979) citado por Rosa et al., (2002) concluíram que a piora da qualidade da casca, associada ao aumento da idade da matriz, determina maior perda de peso em ovos durante a incubação e elevação da taxa de mortalidade embrionária, com consequente queda da eclodibilidade dos ovos.

Quanto ao tratamento de ovos com microtrincas, os danos e lesões na casca aumentam a mortalidade embrionária devido o aumento da perda evaporativa (NARAHARI et al., 2000). Narush e Romanov (2002) demonstraram que a porosidade e a espessura da casca são fatores de maior influência sobre o desenvolvimento embrionário e Peebles E Macdaniel (2004) citado por Santos et al. (2007) que há uma associação entre qualidade de casca e eclodibilidade.

Apesar dos ovos deformados, com microtrincas e com densidade 1070 apresentarem maior grau de contaminação em relação aos outros tratamentos, os resultados foram inferiores aos apresentados por Santoset al. (2007) que obtiveram $24,3 \%$ de contaminação em ovos deformados e $10,9 \%$ em ovos trincados. Ressalta-se que os ovos utilizados neste estudo passaram por 
ROVARIS, E. et al., Avaliação da incubação artificial de ovos deformados em matrizes pesadas. PUBVET, Londrina, V. 8, N. 18, Ed. 267, Art. 1777, Setembro, 2014.

processo de fumigação na granja, o que pode ter eliminado muitos contaminantes da casca, o que deve ter contribuído para índices de contaminação não terem sido muito elevados. Segundo Elguera (1999) o gás formado no processo de fumigação obtidoao combinar cristais de permanganato de potássio com formol líquido, tem ação bactericida de contato é muito efetivo contra salmonelas, coliformes e outras bactérias patogênicas.

Ramos (2011) avaliando ovos de aves avós também obteve piores eclosões em ovos com menor densidade, $61 \%, 70,5 \%, 74,42 \%$ e $76,37 \%$ de eclosão média em ovos com densidade de 1070,1075, 1080 e 1085, respectivamente.

Os ovos incubados com o pólo invertido apresentaram uma menor eclosão, 53,8\%, seguidos pelos ovos com microtrincas com $73,73 \%$ e ovos deformados com 82,05\% em relação aos outros tratamentos. Santoset al. (2007) também obtiveram eclodibilidade inferior em relação aos ovos deformados $(21,21 \%)$ e aos ovos trincandos $(57,3 \%)$.

Schmidt et al. (2002), consideraram que a forma do ovo pode influenciar as condições requeridas para uma ótima incubação quando associada a uma alteração na porosidade da casca, influenciando a perda de água durante o processo.

O ovo considerado ideal para incubação é o de formato ovalado, conforme citado por Albino et al. (2005), o qual descreve que ovos com formatos compridos ou excessivamente redondos possuem tendência de quebrar durante o processo de viragem nas incubadoras. O processo de viragem é realizado durante o processo de incubação, isto deve ser feito para prevenir a aderência do embrião à membrana da casca do ovo, principalmente durante a primeira semana da incubação. A viragem ajuda no desenvolvimento das membranas embrionárias, na medida que o embrião se desenvolve, e aumenta sua capacidade de produzir calor, também ajuda na circulação do ar e auxilia na redução da temperatura.

Ovos pequenos normalmente procedem de matrizes em início de produção e pintinhos oriundos destes ovos tendem a apresentar desenvolvimento 
ROVARIS, E. et al., Avaliação da incubação artificial de ovos deformados em matrizes pesadas. PUBVET, Londrina, V. 8, N. 18, Ed. 267, Art. 1777, Setembro, 2014.

inferior daqueles oriundos das matrizes mais velhas (produzem ovos maiores), pois seus ovos contem menor quantidade de albúmen e gema e maior densidade do albúmen. O albúmen denso atua como uma barreira para evaporação e difusão de água e gases entre o interior do ovo e o meio ambiente da incubadora, provavelmente dificulta a obtenção de oxigênio pelo embrião, o que atrasa seu desenvolvimento e reduz sua eclodibilidade (MAIORKA et. al., 2003), isto pode explicar o pior índice de eclosão dos ovos pequenos ( 45 a 47g) em relação ao tratamento controle. Rosa et. al. (2002) ao avaliarem os efeitos da idade damatriz do peso do ovo sobre o resultado da incubação concluíram que ovos de matrizes na fase inicial de postura tiveram uma menor eclodibilidade e uma mortalidade embrionária total maior, melhorando estes índices com $o$ aumento da idade da matriz e consequentemente com o aumento do tamanho do ovo, os melhores resultados obtidos foram ao redor da $39^{a}$ semana de idade e com ovos ao redor das $65 \mathrm{~g}$.

Os ovos posicionados com o pólo invertido obtiveram a pior eclosão. Segundo Brito (2006) os ovos devem ser posicionados com a ponta fina para baixo, ou seja, com a câmara de ar voltada para cima. Caso contrário, o desenvolvimento do pintinho será com a cabeça virada para ponta fina que não existe câmara de ar. Ocorrendo assim mortalidade que podem ser maior que $10 \%$ e uma taxa superior a $40 \%$ de refugagem.

Os dados deste estudo concordam com Noleto et al. (2012) que obtiveram $53 \%$ de eclodibilidade em ovos de matrizes Cobb $-500^{R}$ incubados com o pólo invertido.

$\mathrm{Na}$ tabela 02 apresentam-se os dados de custos aproximados da incubação de ovos em um incubatório industrial e o valor do pinto de $1 \mathrm{dia}$ em decorrência da eclodibilidade, considerando apenas os custos produtivos do incubatório. 
ROVARIS, E. et al., Avaliação da incubação artificial de ovos deformados em matrizes pesadas. PUBVET, Londrina, V. 8, N. 18, Ed. 267, Art. 1777, Setembro, 2014.

Tabela 2. Custo aproximado da incubação dos ovos em incubatório industrial e preço do pinto em decorrência da eclodibilidade.

\begin{tabular}{|c|c|c|c|c|c|c|}
\hline Índices & $\begin{array}{l}\text { Ovos } \\
\text { tortos }\end{array}$ & $\begin{array}{c}\text { Ovos } \\
\text { pequenos } \\
(42 \mathrm{a} \\
47 \mathrm{~g})\end{array}$ & $\begin{array}{c}\text { Ovos com } \\
\text { microtrincas }\end{array}$ & $\begin{array}{c}\text { Ovos com } \\
\text { densidade } \\
1070\end{array}$ & $\begin{array}{c}\text { Ovos } \\
\text { com } \\
\text { pólo } \\
\text { invertido }\end{array}$ & Controle \\
\hline $\begin{array}{c}\text { Eclosão de } \\
\text { pintos viáveis } \\
\text { Número de }\end{array}$ & 82,05 & 85,76 & 73,73 & 84,89 & 53,08 & 91,11 \\
\hline $\begin{array}{c}\text { ovos } \\
\text { incubados } \\
\text { (simulação) }\end{array}$ & 800000 & 800000 & 800000 & 800000 & 800000 & 800000 \\
\hline $\begin{array}{c}\text { Valor da } \\
\text { incubação/ovo } \\
(\mathrm{R} \$)\end{array}$ & 0,11 & 0,11 & 0,11 & 0,11 & 0,11 & 0,11 \\
\hline $\begin{array}{l}\text { Número de } \\
\text { pintos } \\
\text { eclodidos }\end{array}$ & 656400 & 686080 & 589840 & 679120 & 424640 & 728880 \\
\hline $\begin{array}{l}\text { Valor pinto/1 } \\
\text { dia }(R \$)\end{array}$ & 0,134 & 0,128 & 0,149 & 0,130 & 0,207 & 0,121 \\
\hline
\end{tabular}

Em relação aos dados da tabela 2 observa-se que o valor do pinto de 1 dia varia dependendo do defeito dos ovos, sendo que o menor custo é para produzir pintinhos oriundos dos ovos do tratamento 6 (controle), nota-se por exemplo que os ovos com microtrincas (tratamento 3 ) apresentam diferença de $R \$ 0,028$ no preço do pinto de 1 dia em relação ao tratamento controle, considerando a incubação de 800000 ovos, isto equivale a uma diferença do de $R \$ 22400,00$ no custo de produção dos pintinhos.

Muitos destes defeitos dos ovos analisados podem ser evitados realizandose manejos corretos na granja, como posicionar o ovo adequadamente, ter 
ROVARIS, E. et al., Avaliação da incubação artificial de ovos deformados em matrizes pesadas. PUBVET, Londrina, V. 8, N. 18, Ed. 267, Art. 1777, Setembro, 2014.

cuidado na manipulação para evitar microtrincas, realizar uma correta desinfecção dos ovos para evitar ou diminuir as contaminações, manter um ambiente adequado e sanitariamente controlado evitando que as aves sofram calor ou doenças diminuindo a formação de ovos cascas finas e/ou tortos.

Para o incubatório obter altos índices de eclodibilidade que é o objetivo, faz-se necessário a classificação dos ovos na granja ou no incubatório descartando ovos que apresentem anormalidades (com tortos, com microtrincas, com baixa densidade) e é necessário posicioná-los na bandeja com a câmara de ar para cima.

Os menores custos foram obtidos da incubação de ovos sem defeitos, porém a decisão de descartá-los ou não vai depender do mercado, ou seja, da demanda que a aumenta ou diminui o valor do pinto de 1 dia.

\section{Conclusões}

Os ovos com pólo invertido e com microtrincas apresentaram os piores índices de eclodibilidade.

A incubação de ovos normais obteve melhores índices de eclodibilidade, mortalidade embrionária e de pintos de segunda.

Os menores índices de contaminação foram obtidos nos ovos pequenos (42 a 47g) e os incubados com pólo invertido.

\section{Referências}

ALBINO, L. F. T. Criação de Frango e Galinha Caipira: Avicultura Alternativa. 2. ed. Viçosa, M. G. 2005.p. 94-109.

BRITO, A. B. Problemas microbiológicos na incubação artificial. Poli-Nutri, 2006.

COBB-VANTRES. Guia de manejo da incubação.Guapiaçu - SP, Brasil. 2008.

ELGUERA, M.A. Relação entre o manejo de reprodutoras de carne a qualidade de ovos incubáveis. In: Simpósio técnico sobre matrizes de frangos de corte, 2., Chapecó, 1999. Anais...Chapecó: Acav/Embrapa,1999. p.17-27. 
GONZALES, E.; CAFÉ, M.B. Produção de pintinhos com qualidade total. In: MACARI, M.;GONZÁLES, E. Manejo da incubação.2. D. Campinas: FACTA, 2003. Cap. 5.3, p. 516-526.

MAIORKA, A. et al. Fatores que afetam a eclodibilidade dos pintos. In: MACARI, M.; NASCIMENTO, V.P.; SALLE, T.P.S. Biologia das aves. In: MACARI, M.; GONZALES, E. (Eds.) Manejo da incubação. 2.ed. Campinas: Fundação APINCO de Ciência e Tecnologia Avícolas, 2003. p. 34-50.

NARAHARI, D. et al. Methods to improve the hatchability of checked chicken eggs. British Poultry Science, v.41, n.2, p.178-181, 2000.

NARUSHIN, V.G.; ROMANOV, M.N. Egg physical characteristics and hatchability. World'sPoultry Science Journal, v.58, n.3, p.297-303, 2002.

NOLETO, A. R. Influência da posição dos ovos de matrizes pesadas durante a incubação sobre os índices de eclodibilidade, eclosão total e mortalidade embrionária. XXII Congresso brasileiro de zootecnia. Cuiabá, 2012.

RAMOS, A. C., Estudo comparativo da eclosão, perda de peso e mortalidade embrionária por densidade de ovos de avós da $\mathbf{2 8}^{a}$ a $34^{a}$ semana de vida. 2011. $21 p$. Monografia (conclusão de curso de medicina veterinária) Universidade do Rio Grande do Sul, Porto Alegre.

ROSA, P. S.; GUIDONI, L.A.; LIMA, L.I.; BERSCH, R. X. F. Influência da temperatura de incubação em ovos de matrizes de corte com diferentes idades e classificados por peso sobre os resultados de incubação. Revista Brasileira de Zootecnia, v.31, n.2, p.1011-1016, 2002.

ROSA, P. S. e ÁVILA, S. V. Variáveis relacionadas ao rendimento da Incubação de ovos em matrizes de frangos de corte. Comunicado Técnico/Embrapa suínos e aves.n. 246, p. 1-3, concórdia, 2000.

SANTOS, J.FORNARI, M. C.; TÉO, A. M.. Influência da qualidade da casca do ovo sobre índices de produtividade de um incubatório industrial. Ciência Rural, Santa Maria, v.37,n.2, p. 524527, mar-abr. 2007.

SILVA, A. F. Influência dos tempos de aquecimento e armazenamento de ovos férteis de produtoras pesadas sobre a eclodibilidade e características de pintos de 1 dia. 2005. 102p.Tese (mestrado)Universidade de São Paulo,Pirassununga.

SCHMIDT, G.S.; FIGUEIREDO, E.A.P.; AVILA, V.S.Incubação: estocagem de ovos férteis.Comunicado Técnico/Empraba suínos e aves. n. 303, p.5, Concórdia: Embrapa Suínos e Aves, 2002. 5p.

TANURE, C.B.G.S.; CAFÉ, N.S.M.; BAIÃO, N.C. et al. Efeitos da idade da matriz leve e do período de armazenamento de ovos incubáveis no rendimento de incubação. Arq. Bras. Med. Vet. Zootec., v.61, n.6, p.1391-1396, 2009.

TONA, K.; BAMELIS, F.; DE KETELAERE, B.; BRUGGEMAN, V.; MORAES, V.M.B.; BUYSE, J.; ONAGBESAN, O.; DECUYPERE, E. Effects of egg storage time on spread of hatch, chick quality, and chick juvenile growth. Poultry Science, v.82, n.2, p.736-741, 2003. 